\title{
The Affordable Care Act (ACA): It Gets Personal, Very Quickly
}

DOI: $10.3766 /$ jaaa.30.8.1
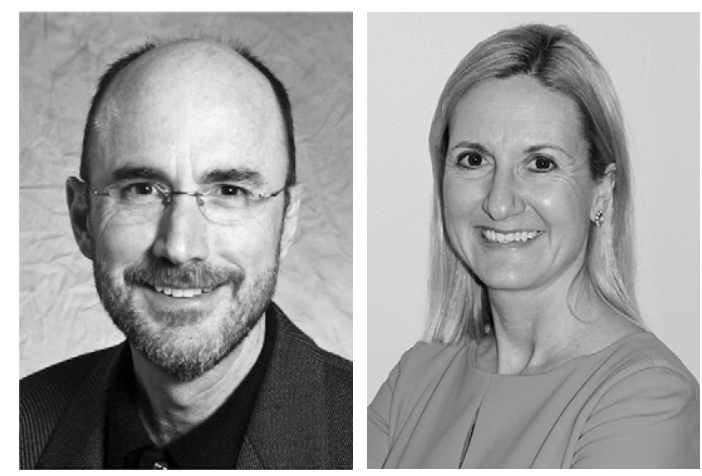

I

(Gary Jacobson) am part of that aging demographic called the "Baby Boomers." You know us. We are the older faculty and clinicians. We are the ones who are still having fun working mostly because we enjoy it, not necessarily because we have to.

Unfortunately, there are more than a few of us Boomers who have another reason to continue working. That reason is having one of the myriad of preexisting health conditions that could make us completely uninsurable (or, at least, uninsurable for the health condition/s about which we are most concerned), if we were forced to purchase health insurance privately.

By now, you have no doubt heard of the Affordable Care Act (ACA). The issue of how to secure health insurance after retirement became a major issue for individuals not yet eligible for Medicare when the current presidential administration made one of its goals the repeal of the ACA.

Provisions of the Affordable Care Act stipulate that: 1) uninsured individuals may purchase comprehensive health insurance through health insurance marketplaces, or exchanges, and 2) these individuals cannot be denied coverage even if they have a preexisting medical condition. The latter provision means that even individuals who were uninsurable previously because they had health challenges could secure a health insurance policy that would cover any preexisting conditions. In addition, the ACA includes a provision that prohibits health insurers from imposing an annual or lifetime limit on benefits. This was designed to protect patients with very high cost or long-lasting conditions from "maxing out" their health insurance benefits.

This editorial is not meant to be a debate on the merits or demerits of the ACA. It is a look at what the ACA and its protections mean for our patients. It is well-known that the success of the ACA was dependent, in part, on the willingness of young and healthy individuals to purchase insurance on the exchange to offset the costs of enrolling older and sicker individuals.

\section{Statistics tell the story}

By way of background, it is estimated that 27 percent of Americans under the age of 65 years would not be insurable if they had to purchase health insurance on the open market in the era prior to the ACA (Claxton et al, 2019). Fifty three percent of individuals report having someone in their home with a pre-existing condition (Claxton et al, 2019), according to a Kaiser Family Foundation poll. Thirty percent of women and 24 percent of men have been reported to have declinable pre-existing conditions (Claxton et al, 2019).

In my (GJ) home state of Tennessee, it has been estimated that 32 percent of the population has declinable pre-existing conditions. Further, at present, it has been estimated that 52 million Americans who have declinable pre-existing conditions have health coverage through an employer or through Medicaid or Medicare (Claxton et al, 2019).

Individuals who lose health insurance benefits due to loss of employment, divorce, or because they have turned 26 years old and cannot remain on their parent's insurance (as was the case for my daughter: GJ) must purchase insurance privately on the open market and that, of course, is expensive. Moreover, it has been reported that 18 percent of the individual market applications are denied. The denial rates were 5 percent for children and 29 percent for adults (Claxton et al, 2019).

\section{Considering pre-existing conditions}

If the current administration is successful in its effort to repeal the ACA, those with pre-existing conditions will either become entirely uninsurable or, at the very least, will be uninsurable for the conditions for which they have current needs or may require treatment in the future.

An insurance company's practice of refusing to insure patients for pre-existing medical conditions is related to insurance "underwriting," or the evaluation of risk for an insurer based on the amount of coverage a client receives and how much they pay for that coverage. 
You might be surprised at what constitutes a preexisting condition. Do you have a history of migraine headache? Well, if you do, you should be aware that migraine headache is considered a pre-existing condition. How about, vertigo? Is vertigo considered a pre-existing condition? Yup, it sure is.

How about our patients who have congenital severeto-profound hearing impairments? Hey, wait a minute now-hold your horses-this is hitting pretty close to home. Well, if the hearing loss was present at birth, that could be considered a pre-existing condition.

Before the ACA, most health insurance was medically underwritten, which means that the insurance companies would evaluate a customer's health history, current health status, and other risk factors to determine how much of a potential risk they would be to insure.

When health insurance is provided as a benefit by a large company, it is possible for the employer or plan administrator to say to the insurance company: "If you want our business, you are going to have to assume a greater degree of risk. That is, you will have to insure even those employees who have serious chronic disease if you want to receive the premiums from the thousands of other healthier workers we employ."

\section{Some specifics on insurance denials}

You may or may not be aware that medical underwriters can deny individuals with health insurance if they have been unlucky enough to have, or have had, diseases including cancer, diabetes, kidney disease, obesity, Parkinson's disease, or even if they are pregnant (Claxton et al, 2019). They can deny coverage to individuals who are taking the following commonly prescribed medications: Humira, Stelara, Tamoxifen, Plavix, Humalog, Zyprexa, Clomid, and Remicade (Claxton et al, 2019). Lastly, individuals may be denied coverage outright if they engage in dangerous occupations, including those who are active military personnel, law enforcement personnel, pilots, professional athletes, or taxi drivers (to name a few).

Claxton et al (2019) described strategies medical underwriters have employed to ensure their financial success in insuring individuals with common diseases and disorders such as high cholesterol, migraine headache, vertigo, urinary tract infections, depression, ear infections, anxiety, and skin cancer. These strategies include: rate-up, exclusion rider, increased deductible, and modified benefits.

The rate-up strategy is exactly what it sounds like. An applicant might be charged a premium (e.g., 150 percent of the customary rate) compared to the rate quoted for someone without that condition. An exclusion rider excludes a particular pre-existing condition from coverage, period. The increased-deductible strategy means that the insured would have to exceed a larger out-of-pocket threshold in general, or for a specific health condition, before the insurance company would begin paying for the assessment and/or treatment of the condition in question. An example of modified benefits would be a health insurance policy that does not include prescription drug coverage (Claxton et al, 2019).

\section{Pre-existing conditions and congential hearing loss}

Aside from my own selfish concerns (as an individual with possible pre-existing conditions: GJ), I became interested in the issue of pre-existing conditions when I began asking questions about the relationship between pre-existing conditions and congenital hearing loss. After all, the name of the diagnosis of congenital hearing loss suggests a hearing loss that exists prior to birth.

In the pre-ACA health insurance market, insurance companies typically defined a pre-existing condition very broadly as any health problem or condition that existed before an individual applied for a health insurance policy or enrolled in a new health plan. Thus, the insurance company had the unilateral power to decide whether or not someone with congenital hearing loss had a pre-existing condition.

Accordingly, the insurer could have declined coverage. Alternately, an insurer could have provided coverage to an individual with congenital hearing loss, but charged them a much higher premium, placed an annual or lifetime limit on received benefits, or provided insurance coverage for everything except the congenital hearing loss.

It is worth noting that, under the ACA, these practices are not allowed. Insurers must offer coverage to all. Premiums can only vary based on age, ZIP Code, tobacco use, and family size. In addition, the ACA prohibits health plans, even employer-based plans, from putting annual or lifetime limits on received benefits.

\section{Other approaches to weaken ACA's patient protections}

It is also important to realize that, while the very public debate has been focused on repeal of the ACA, opponents of the law also have been working to relax existing regulations in an effort to make non-ACA compliant health insurance coverage more accessible. This includes "association" health plans for small businesses and short-term health plans for individuals.

Association health plans can charge higher premiums based on an individual's medical history. Short-term health plans typically include blanket exclusions for pre-existing conditions and allow higher premiums based on an individual's medical history. 
It is critical that health-care providers are aware of these developments and that consumers of these types of plans are fully informed about the pros and cons of these policies.

\section{Helping our patients}

In the current political environment, it is impossible to predict what will happen from one day to the next. Available statistics, however, provide a stark look at the situation. Twenty-eight percent of 18- to 64-yearolds, or nearly 52 million non-elderly adults, have at least one potentially declinable health condition, according to an analysis of the National Health Interview Survey (NHIS) conducted by the Kaiser Family Foundation.

Accordingly, regardless of your political affiliation, or how you feel about specific provisions of the ACA, or whether you do-or do not-believe that health insurance is a basic human right, we all should be able to agree that it is our professional responsibility to advocate on behalf of our patients.

Many of these individuals have been unfortunate enough to lose their life's savings by becoming seriously ill in our great nation. We should all be aware that there are critical provisions of the ACA that need and deserve protection, including those that prevent insurance companies from denying coverage for preexisting conditions.

It is a certainty that every one of us knows, works with, or lives with someone with a pre-existing condition. This is an issue that becomes very personal, very quickly.

What can you do to help? Speak up and tell your elected representatives why these provisions are so important to the services that we provide. Also, explain to your colleagues and patients how these provisions help preserve the care that they provide and receive.

Gary P. Jacobson, PhD Editor-in-Chief

Susan Pilch, JD

\section{REFERENCE}

Claxton G, Cox C, Levitt L, Pollitz K. (2016) Pre-existing conditions and medical underwriting in the individual insurance market prior to the ACA. https://www.kff.org/health-reform/issue-brief/ pre-existing-conditions-and-medical-underwriting-in-the-individualinsurance-market-prior-to-the-aca. 